\title{
Influência de aditivo retardador de pega na reolo- gia de pasta de gesso
}

\author{
Queiroz, D. M. N. \\ Escola Politécnica de Pernambuco \\ Universidade de Pernambuco \\ 50.720-001 - Recife, Brasil \\ deborahnqueiroz@gmail.com
}

Resumo Devido às suas propriedades e ao baixo custo, o gesso tem se tornado muito interessante para o revestimento interno de paredes. Sua utilização principal, no Brasil, está voltada para a execução de painéis pré-moldados para divisórias, forros e molduras. No entanto, assim como outros materiais de construção, o gesso é um grande gerador de resíduos. A quantidade expressiva desses resíduos e sua destinação inadequada causam grandes impactos ambientais, econômicos e sociais. Com isso, torna-se necessária a busca por soluções que resolvam esses problemas. Objetiva-se, com esta pesquisa, estudar o comportamento reológico do gesso sob a influência de aditivo retardador de pega. Para isso serão feitos ensaios de squeeze flow. $O$ resultado esperado com a adição do retardador de pega - bórax, é o possível aumento do tempo útil de aplicação do revestimento, diminuindo a geração de resíduos. .

\footnotetext{
Abstract Due to its properties and low cost, the plaster has become very interesting for covering walls. However, like other construction materials, gypsum is a major generator of waste. A significant number of improper waste disposal cause great environmental, economic and social impacts. Thus, it becomes necessary to search for solutions that solve those problems. The aim of this research is to study the rheological behavior of the plaster under the influence of additive time retardant. For this, test will be made using squeeze flow. The expected outcome with the addition of retarder - borax, is the possible increase in the time of application of the coating, reducing waste generation.
} 


\section{Introdução}

O gesso era usado como material de construção desde o tempo dos egípcios, em ornamentação nas paredes interiores de pirâmides, assim como na elaboração de afrescos em igrejas e capelas no período românico. [1]

No Brasil, atualmente, a maior parte do gesso ainda é empregada na construção civil, seja para fundição - na fabricação de pré-moldados, placas, blocos e chapas de gesso - ou para revestimento - em paredes e tetos.

\subsection{Justificativa}

Na indústria da construção civil a utilização do gesso só tende a aumentar, pois se observa uma grande produtividade, e apesar de todo o desperdício, ainda é um revestimento de baixo custo. $\mathrm{O}$ custo poderia ser reduzido ainda mais, caso não houvesse a geração de tanto resíduo como é apresentado no cenário atual.

Como muitas empresas, que utilizam o gesso para o revestimento interno de paredes, não fornecem treinamento adequado para sua mão-de-obra a probabilidade de geração de resíduos é muito grande. Com a adição do bórax pode-se retardar a pega do gesso, aumentando o seu tempo de trabalhabilidade e tendo uma possível diminuição dos resíduos gerados.

\subsection{Justificativa}

Este projeto de pesquisa tem como objetivo geral estudar a influência de aditivo retardador de pega na reologia da pasta de gesso visando diminuir a geração de resíduos.

Para que o objetivo geral deste projeto seja atingido, os seguintes objetivos específicos são visados:

- realizar ensaios de squeeze flow na pasta de gesso com e sem adição do retardador de pega - bórax;

- estudar a influência do retardador no tempo de pega da pasta do gesso.

\section{Introdução}

O gesso é um aglomerante produzido a partir da gipsita, composto basicamente de sulfato de cálcio dihidratado. O processo industrial para a formação do gesso se dá pela calcinação dos fragmentos da gipsita num forno rotativo a cerca de $160^{\circ} \mathrm{C}$. Neste processo o material perde água, formando assim o sulfato de cálcio semihidratado. Uma vez calcinado, o material é moído, formando o característico pó branco. [2]
O minério da gipsita se origina em bacias sedimentares. No território brasileiro os principais depósitos de gipsita ocorrem associados às bacias sedimentares conhecidas como Bacia Sedimentar do Araripe (Piauí, Ceará e Pernambuco); Bacia Potiguar (Rio Grande do Norte); Bacia do Recôncavo (Bahia); Bacia do Parnaíba (Maranhão e Tocantins) e Bacia Amazônica (Amazonas e Pará). Do ponto de vista econômico, os mais importantes depósitos de gipsita estão localizadas na Bacia Sedimentar do Araripe, sobretudo em Pernambuco. [3]

Devido à sua ótima qualidade e baixo custo, o gesso vem sendo cada vez mais utilizado na construção civil. Verifica-se, também, a maior produtividade já que possui um rápido processo de aplicação, e um bom acabamento final, podendo ser aplicada a pintura sem ser necessária a aplicação da massa corrida. Porém, por conta da alta velocidade de endurecimento, é produzida uma grande quantidade de resíduos. Estima-se que o índice de desperdício seja equivalente a $45 \%$ do gesso utilizado. [4]

O desperdício causa tanto problemas econômicos quanto ambientais, devido ao grande custo para a destinação correta dos resíduos.

A resolução No 307 do CONAMA (2002) definiu diretrizes para a gestão de resíduos da construção civil e classificou o gesso como um resíduo de classe $\mathrm{C}$, ou seja, não existem tecnologias economicamente viáveis para sua reciclagem ou reutilização. Em maio de 2011, a resolução $\mathrm{N}^{\circ} 431$ do CONAMA (2011) definiu o gesso como classe $\mathrm{B}$, que o torna reciclável. No entanto, esses resíduos não podem ser misturados a outros materiais, para evitar uma possível contaminação. [5]

A redução do desperdício deve ser prioridade da indústria, pois o custo de material perdido junto com a geração de resíduos pode afetar a competitividade do material.

Visando aumentar o tempo de pega do material é comum a utilização de grandes teores de água, porém é formada uma pasta muito fluida para a aplicação. Uma solução encontrada foi a adição de retardadores de pega, que aumentam o tempo útil do gesso, mas corre o risco de reduzir demasiadamente a sua consistência inicial. Será realizado um estudo do comportamento reológico do gesso juntamente com um aditivo retardador de pega.

Usou-se na pesquisa o bórax, como aditivo retardador de tempo de pega. Ele tem como fórmula química $\mathrm{Na}_{2} \mathrm{~B}_{4} \mathrm{O}_{7} \cdot 10 \mathrm{H}_{2} \mathrm{O}$, ele reage com os íons cálcio para formar borato de cálcio insolúvel. Este borato deposita-se na superfície dos cristais, formando uma camada insolúvel em sua volta, a qual interfere em seu crescimento, retardando assim a pega do gesso (PAPO, 1989). 
A forma de atuação do bórax no tempo de pega das pastas de gesso, segundo os diferentes pesquisadores, é direta sobre o cristal que se está formando no momento da hidratação; o bórax atrasa a formação de cristais, atrasando a precipitação e, portanto prolongando o tempo de pega. [6]

\section{Metodologia}

Para a realização do estudo foi coletada uma amostra de gesso natural para revestimento e uma amostra do bórax, aditivo retardador de pega, adicionado nas proporções $0,4 \%, 0,6 \%$ e $0,8 \%$. A dosagem do bórax foi determinada a partir do estudo de Costes (1990), que afirma ser um dos retardadores de pega mais empregados na França, com uma dosagem de $20 \mathrm{~g} / \mathrm{L}$ de água, equivalente a $1 \%$.

Inicialmente foi determinada a relação água/gesso pelo ensaio de consistência segundo a norma DIN 1168 (1975). Pesou-se $100 \mathrm{~g}$ de água num béquer e foi adicionando gesso até saturar. Anotou-se a quantidade de gesso utilizada, conseguindo obter a relação água/gesso de 0,72.

O procedimento de mistura do gesso foi feito de acordo com a norma NBR 12128 (ABNT, 1991). Porém o processo de homogeneização da pasta foi realizado manualmente, visando atingir a frequência de uma volta por segundo.

Os ensaios de caracterização realizados foram:

- tempo de pega para a pasta de gesso com e sem aditivo - DIN 1168 (1975);

- massa unitária e granulometria para o gesso em pó NBR 12127 (ABNT, 1991);

- dureza e resistência à compressão para a pasta de gesso com e sem aditivo - NBR 12129 (ABNT, 1991).

Posteriormente iniciaram-se os ensaios de squeeze flow para a pasta de gesso com e sem aditivo, que consiste na compressão de uma amostra cilíndrica entre duas placas paralelas. O método é simples e versátil, sendo capaz de avaliar com precisão materiais em ampla faixa de consistência e em velocidade e grau de deformação variável. $\mathrm{O}$ ensaio pode ser realizado com controle de força ou por deslocamento. Como base, foi tomado o estudo de AGOPYAN et al. (2005). [7]

\section{Resultado}

\subsection{Estilos}

O ensaio de tempo de pega foi realizado de acordo com a norma DIN 1168 (1975). Com a pasta do gesso, fez-se um disco com diâmetro de, aproximadamente, $10 \mathrm{~cm}$ (Foto 1). O início do tempo de pega deu-se, quando, ao cortar o disco com uma espátula, ele não voltou a se unir, e o fim de pega, ao pressionar o gesso, a impressão digital não foi deixada. Os resultados estão apresentados no Quadro 2.

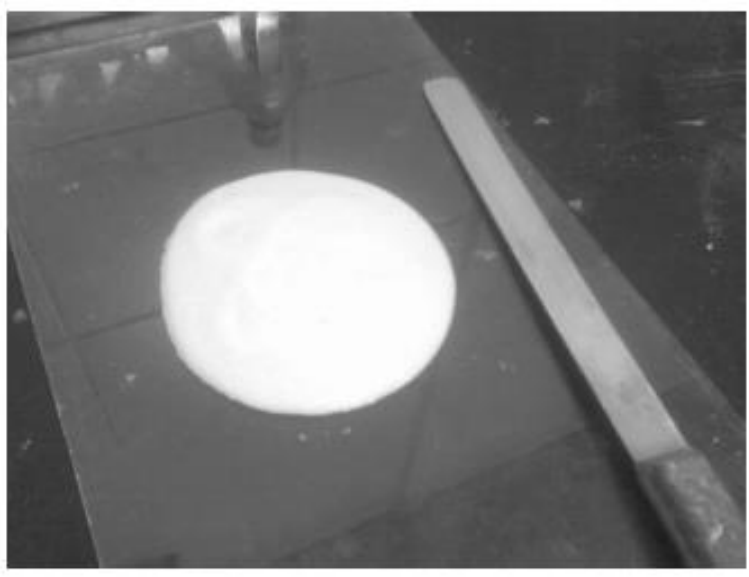

Foto 1 - Pasta de gesso com diâmetro aproximado de $10 \mathrm{~cm}$

A amostra ensaiada de gesso puro, não apresentou um fim de pega maior que 45 minutos, como pede a norma NBR 13207 (ABNT, 1994), com a adição do bórax tem um aumento considerável com relação a essa propriedade.

Quadro 2 - Tempo de pega do gesso com e sem aditivo retardador de pega

\begin{tabular}{|l|l|lr|lr|lr|}
\hline $\begin{array}{l}\text { Tempo } \\
\text { de Pega }\end{array}$ & Gesso Puro & $\begin{array}{l}\text { Gesso }+ \\
0,4 \% \\
\text { bórax }\end{array}$ & $\begin{array}{l}\text { Gesso } \\
0,6 \% \\
\text { bórax }\end{array}$ & $\begin{array}{l}\text { Gesso de } \\
0,8 \% \\
\text { bórax }\end{array}$ \\
\hline $\begin{array}{l}\text { Início } \\
\text { de pega }\end{array}$ & $16 \mathrm{~min} 45 \mathrm{seg}$ & $27 \mathrm{~min}$ & $37 \mathrm{~min} 30 \mathrm{seg}$ & $123 \mathrm{~min} 30 \mathrm{seg}$ \\
\hline $\begin{array}{l}\text { Fim de } \\
\text { pega }\end{array}$ & $41 \mathrm{~min}$ & $50 \mathrm{~min} 15 \mathrm{seg}$ & $70 \mathrm{~min}$ & $187 \mathrm{~min} 40 \mathrm{seg}$ \\
\hline
\end{tabular}

De acordo com os resultados da tabela, é possível notar que, como o previsto, os tempos de pega vão aumentando na medida que a dosagem do bórax é aumentada.

\subsection{Massa unitária e módulo de finura}

Os ensaios de massa unitária e módulo de finura seguiram as recomendações da NBR 12127 (ABNT, 1991). [8]

O gesso apresentou massa unitária de $669,8 \mathrm{Kg} / \mathrm{cm}^{3}$. 
Para o ensaio de granulometria utilizou-se o seguinte procedimento:

- pesar $100 \mathrm{~g}$ do pó do gesso, passar pela peneira de $0,840 \mathrm{~mm}$ e anotar a quantidade que ficou retida;

- colocar o material passante pela peneira de $0,840 \mathrm{~mm}$ na peneira de $0,420 \mathrm{~mm}$, realizar o peneiramento e anotar a quantidade que ficou retida;

- pesar 50g do pó que passou pela peneira de $0,420 \mathrm{~mm}$, transferir para a peneira de $0,210 \mathrm{~mm}$, proceder ao peneiramento e anotar a quantidade que ficou retida;

- transferir o material que passou pela peneira $0,210 \mathrm{~mm}$ para a peneira de $0,105 \mathrm{~mm}$ e, novamente, proceder ao peneiramento, anotando a quantidade que ficar retida.

O módulo de finura do gesso foi determinado como 0,04 caracterizando o material como gesso fino de acordo com a norma NBR 13207 [9] (ABNT 1994) que caracteriza gesso grosso aqueles que possuem módulo de finura maior que 1,10 .

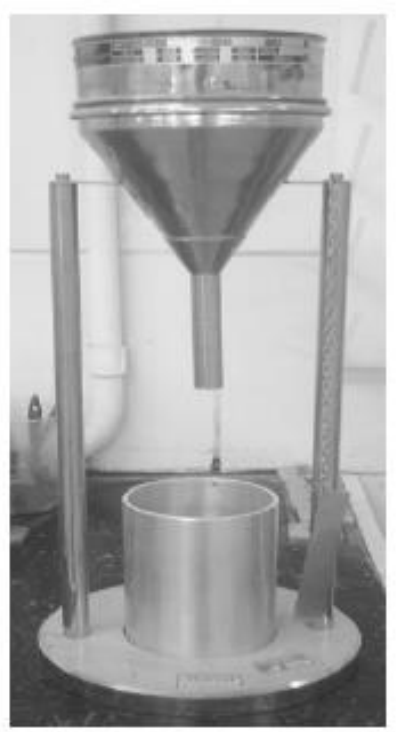

Foto 2 - Aparelho para a determinação de massa unitária

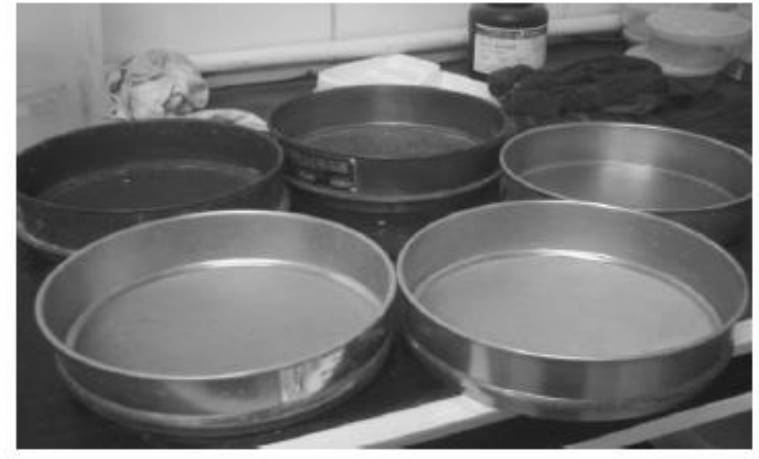

Foto 3 - Peneiras usadas para o ensaio de módulo de finura

Quadro 3 - Quantidade de gesso retido em cada peneira

\begin{tabular}{|l|l|}
\hline Peneira (mm) & $\begin{array}{l}\text { Quantidade de gesso } \\
\text { retido }(\mathbf{g})\end{array}$ \\
\hline 0,840 & 0,35 \\
\hline 0,420 & 0,40 \\
\hline 0,210 & 0,35 \\
\hline 0,105 & 1,34 \\
\hline
\end{tabular}

\subsection{Dureza e resistência à compressão}

Os corpos-de-prova foram moldados de acordo com a norma NBR 12129 (ABNT, 1991) [10], num molde triplo (Foto 4), moldando três corpos de prova simultaneamente. Depois de prontos e secos foram realizados os ensaios de resistência à compressão (Foto 6) e dureza.

Para determinação da dureza foi utilizado o durômetro SHORE C (Foto 4) Para a determinação da resistência à compressão foi utilizada uma máquina universal de ensaios da marca Emic, modelo DL 30.000. Os resultados estão apresentados no Quadro 3. 


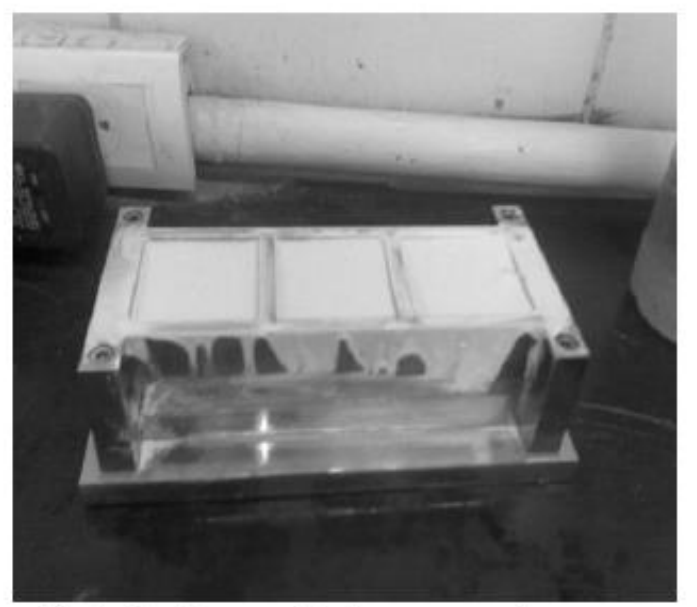

Foto 4 - Preparação dos corpos de prova

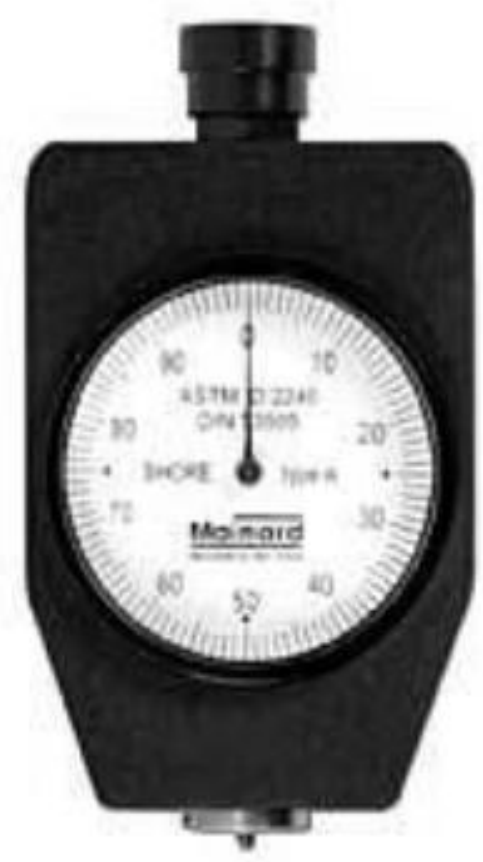

Foto 5-Durômetro SHORE C

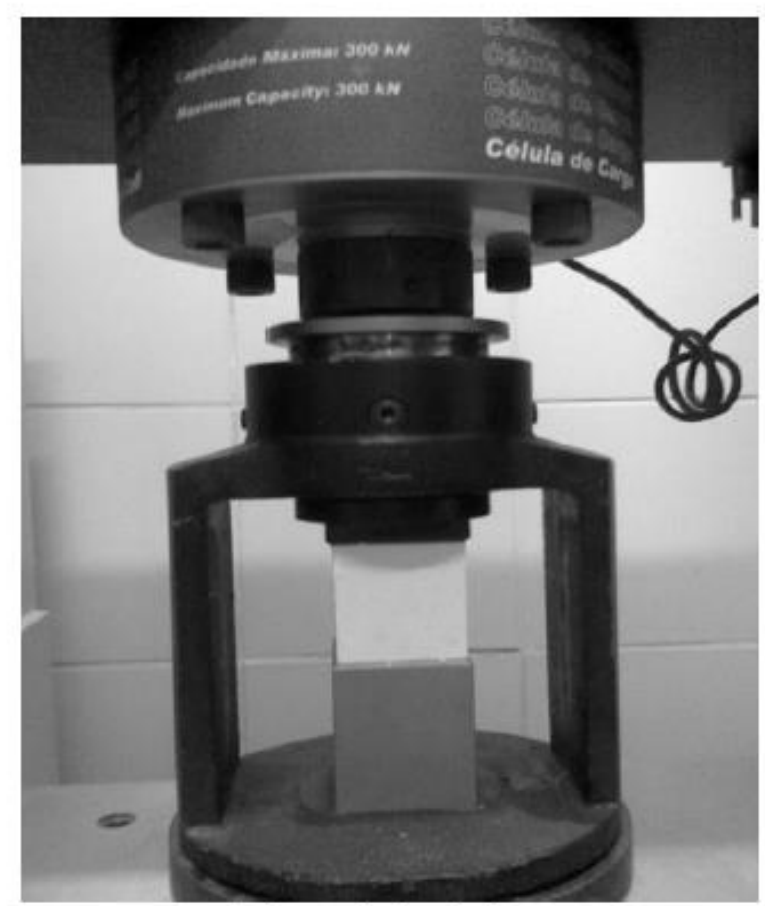

Foto 6 - Ensaio de resistência à compressão

Quadro 4 - Dureza e resistência à compressão de corpos de prova de gesso com e sem aditivo retardador de pega

\begin{tabular}{|l|l|l|l|l|l|}
\hline $\begin{array}{l}\text { Proprie- } \\
\text { dades }\end{array}$ & Unidade & $\begin{array}{l}\text { Gesso } \\
\text { Puro }\end{array}$ & $\begin{array}{l}\text { Gesso + } \\
\mathbf{0 , 4 \%} \\
\text { bórax }\end{array}$ & $\begin{array}{l}\text { Gesso + } \\
\mathbf{0 , 6 \%} \\
\text { bórax }\end{array}$ & $\begin{array}{l}\text { Gesso + } \\
\mathbf{0 , 8 \%} \\
\text { bórax }\end{array}$ \\
\hline Dureza & U.S.C. & 94,3 & 90,1 & 88,6 & 88,7 \\
\hline $\begin{array}{l}\text { Resis- } \\
\text { tência à } \\
\text { com- } \\
\text { pressão }\end{array}$ & Mpa & 3,2 & 3,18 & 3,12 & 3,05 \\
\hline
\end{tabular}

Todos os corpos de prova apresentaram dureza acima do que é pedido pela NBR 13207 (1994). Porém, todos, apresentaram uma baixa resistência à compressão. Como pode ser observado no Quadro 4. De acordo com os resultados tanto a dureza quanto a resistência à compressão, mesmo com a adição do bórax, não sofreram grandes variações, apresentando pequenas diferenças entre si.

\subsection{Squeeze-flow}

Para a realização do ensaio foram moldados corpos de prova (Foto 7) com diâmetro de $100 \mathrm{~mm}$ e com espessura de $10 \mathrm{~mm}$. A velocidade de descida da placa superior foi de $0,1 \mathrm{~mm} / \mathrm{s}$, com deformação máxima de $9 \mathrm{~mm}$ e força máxima de $1000 \mathrm{~N}$. 
Os resultados estão apresentados nos Gráficos 1, 2, 3 e 4 .

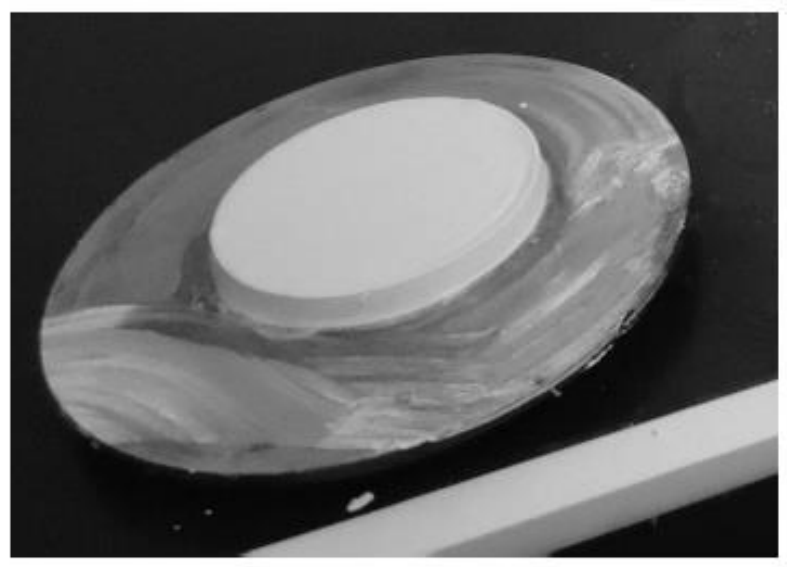

Foto 7 - Corpo de prova

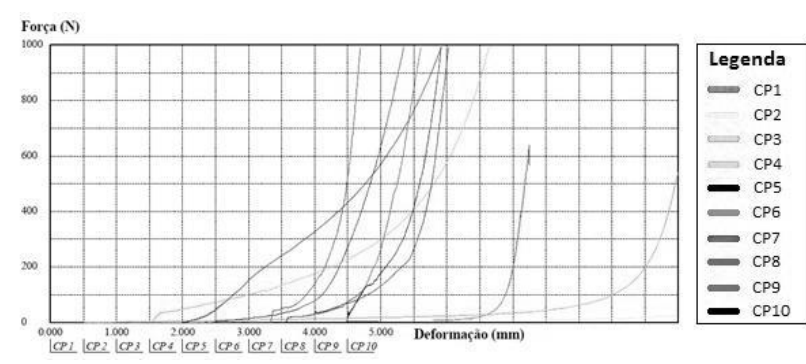

Gráfico 1 - Gráfico do Squeeze-flow do gesso puro

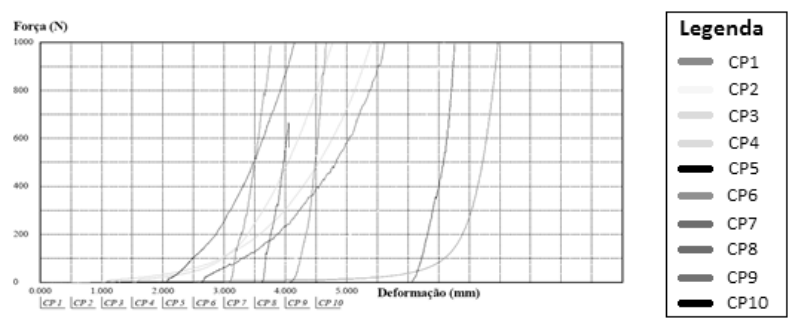

Foto 8 - Gráfico do Squeeze-flow do gesso + 0,4\% de borax

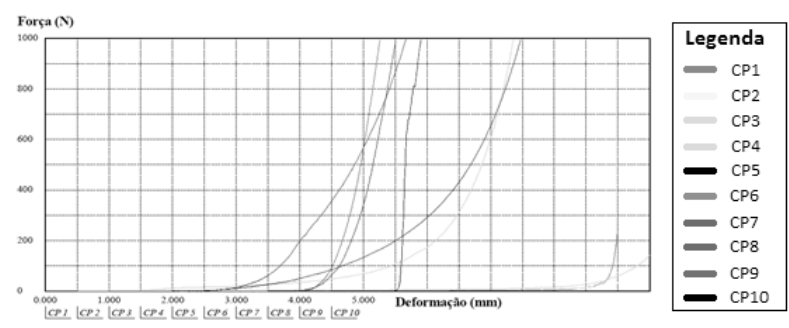

Foto 9 - Gráfico do Squeeze-flow do gesso $+0,6 \%$ de bórax

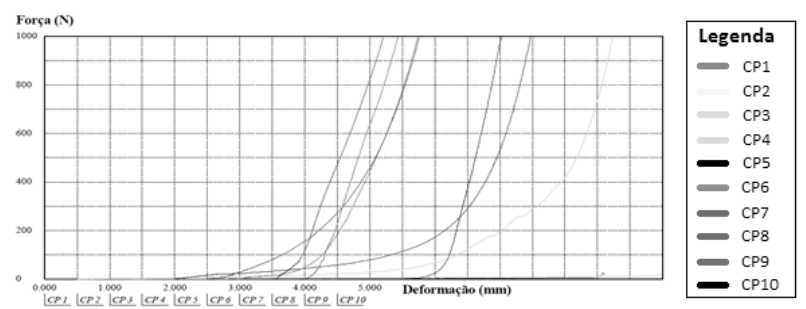

Foto 10 - Gráfico do Squeeze-flow do gesso $+0,8 \%$ de borax

De acordo com os Gráficos 1, 2, 3 e 4 pode-se observar que os primeiros corpos de prova apresentam deformação elástica linear e está relacionado à tensão de escoamento do material. Logo em seguida começam a sofrer deslocamentos intermediários. A compressão resulta em deformação radial elongacional, e de cisalhamento, superando as forças que mantinham o material sob comportamento elástico e, assim, o mesmo flui por deformação plástica.

Nesta etapa o material é capaz de sofrer grandes deformações sem aumento significativo da força, necessária para o deslocamento, que é um comportamento que favorece a produtividade na aplicação.

No terceiro estágio, em grandes deformações, ocorre um aumento expressivo (exponencial) da carga necessária para prosseguir a deformação do material. A aproximação das partículas gera forças restritivas ao fluxo, devido à maior interação por entrelaçamento dos cristais de hidratação do gesso. Este terceiro estágio é caracterizado por um comportamento em que procedimentos de aplicação e acabamento do material tendem a ser dificultados, devido às altas cargas envolvidas.

É importante salientar que cada curva apresentada nos Gráficos 1, 2, 3 e 4 tem seu início indicado pela sigla CP1, CP2, etc. Como exemplo, no Gráfico 4, o CP1 inicia a deformação no zero, o CP2 inicia na deformação $500 \mathrm{~mm}$, o CP3 inicia na deformação $1000 \mathrm{~mm}$, e assim sucessivamente.

Ao verificar os corpos de prova de cada gráfico que correspondem ao tempo de moldagem de aproximadamente 20 minutos, ao alcançarem $100 \mathrm{~N}$, apresentam as seguintes deformações:

gesso puro - 0,75 $\mathrm{mm}$;

- gesso com adição de 0,4\% de bórax - 1,5 mm; 
- gesso com adição de 0,6\% de bórax - 8,5 mm;

e

- gesso com adição de $0,8 \%$ de bórax - ultrapassou os 9 mm, dados como deformação máxima.

Pode-se concluir que quanto maior a quantidade de aditivo adicionado, maior a deformação aplicada, ou seja, com adição de $0,6 \%$ de bórax, a pasta de gesso, aos 20 minutos ainda continua fresca, sendo passível de utilização na aplicação de revestimento interno de parede.

\section{Conclusões}

A adição do bórax na pasta de gesso pode ter seu tempo de pega maximizado e suas características mecânicas preservadas a partir de $0,4 \%$. No entanto, o estudo reológico feito por meio do ensaio de squeeze flow indica que $0,6 \%$ seria um bom indicativo para maximizar o tempo de utilização, uma vez que, aos 20 minutos a pasta ainda apresentou uma deformação de $8,5 \mathrm{~mm}$, ou seja, ainda estava em estado fluido.

A adição do bórax como retardador de pega pode vir a diminuir os custos e o resíduo gerado durante a aplicação do revestimento interno de parede, minimizando, também gastos com transporte e deposição do mesmo, ajudando a diminuir o impacto ambiental.

\section{Referências}

[1] Disponível em: <itaucultural.org.br/aplicexternas/ enciclopedia_ic/index.cfm?fuseaction $=$ termos_texto\&cd_verbete $=54>$. Acesso em: $21 / 07 /$ $201 \overline{1}$.

[2] Balanço Mineral Brasileiro 2011

[3] CInCOTTO, M. A.; AGOPYAN, V; FLORINDO, M. C. O gesso como material de construção - composição química ( $1^{\mathrm{a}}$ parte). In: São Paulo, Instituto de Pesquisas Tecnológicas. Divisão de Edificações. São Paulo, 1998. P.53-56.

[4] AGOPYAN, V et all. Alternativas para a redução de desperdício de materiais nos canteiros de obras. São Paulo, FINEP, ITQC, Escola Politécnica da USP, 1998.

[5] CONSELHO NACIONAL DE MEIO AMBIENTE. Resolução no 307 de 5 de julho de 2002. Estabelece diretrizes e critérios e procedimentos para a gestão dos resíduos da construção. Diário
Oficial da República Federativa do Brasil.

[6] HINCAPIE, A.M.; CINCOTTO, M.A. Seleção de substâncias retardadoras do tempo de pega do gesso de construção. São paulo: escola Politécnica - USP, 1997 (Boletim Técnico).

[7] F. A. CARDOSO, A. K. AGOPYAN, C. CARBONE*, V. M. JOHN, R. G. PILEGGI Caracterização Reológica de Revestimentos à Base de gesso por Squeezeflow.

[8] ASSOCIAÇÃO BRASILEIRA DE NORMAS TÉCNICAS. Gesso para construção civil: determinação das propriedades físicas do pó. - NBR 12127/MB 3468. Rio de Janeiro,1991.

[9] ASSOCIAÇÃO BRASILEIRA DE NORMAS TÉCNICAS. Gesso para construção civil: especificação. NBR 13207. Rio de Janeiro, 1994.

[10] ASSOCIAÇÃO BRASILEIRA DE NORMAS TÉCNICAS. Gesso para construção civil: determinação das propriedades mecânicas. - NBR 12129/MB 3470. Rio de Janeiro, 1991. 